\title{
PREVALÊNCIA DE DEFICIÊNCIA DE VITAMINA A EM PACIENTES COM DOENÇA FALCIFORME NA REGIÃO DE FEIRA DE SANTANA-BA.
}

\section{OLIVEIRA B. B. ${ }^{1}$; GUIMARÃES C. O. S. ${ }^{2}$; ALVAIA M. A. ${ }^{3}$ e BESSA JÚNIOR $\mathrm{J}^{4}$}

1. Pesquisador Voluntário, Graduando em Medicina, Universidade Estadual de Feira de Santana, e-mail: brenobatista07@outlook.com

2. Participante do Grupo de Pesquisa UROS, DSAU, Universidade Estadual de Feira de Santana, e-mail: carioliveira13@outlook.com

\footnotetext{
3. Participante do Grupo de Pesquisa UROS, DSAU, Universidade Estadual de Feira de Santana, e-mail: mateus_alvaia@hotmail.com

4. Orientador, DSAU, Universidade Estadual de Feira de Santana, e-mail: bessa@uefs.br
}

\section{PALAVRAS-CHAVE: Doença Falciforme; Prevalência; Vitamina A.}

\section{INTRODUÇÃO}

A Doença Falciforme (DF) é uma hemoglobinopatia hereditária que representa relevância clínica e epidemiológica na saúde pública brasileira, ao analisar que, em 2001, evidenciou-se oito mil portadores da anemia falciforme no Brasil. (DINIZ, D.; GUEDES, C., 2007). A DF apresenta uma manifestação sintomática bem abrangente, que reflete de forma impactante na qualidade de vida, resultante principalmente da ocorrência de vasooclusões e das crises álgicas, com apresentação de quadros clínicos de priapismo, retinopatia, úlceras de membros inferiores e insuficiência renal crônica. (FELIX; SOUZA; RIBEIRO, 2010).

As comorbidades da DF comprometem a ingesta alimentar, de modo que resulta em um mau estado nutricional, repercutindo na maturação sexual e esquelética e na deficiência de micronutrientes. (OHEMENG, A.; BOADU, I., 2017). O déficit de micronutrientes é evidente, entre outras substâncias, na vitamina A (VA) e correlacionase diretamente com evolução desfavorável da doença.

A VA é um termo abrangente que se aplica aos compostos que atuam como os retinóides (apresentam a estrutura cíclica da beta-ionona: retinol todo-trans, retinal, éster de retilina e o ácido retinólico), com armazenamento, principalmente, nas células estreladas do fígado na forma de éster de retilina. É um micronutriente importante na homeostase corporal, na medida em que se relaciona com quatro processos principais: Sensibilização do fotorreceptor à luz, carreador de unidades manosil na síntese de glicoproteínas e proliferação e diferenciação celular (regulação da expressão gênica) e potencial antioxidante, bem como espermatogênese/síntese de testosterona, regulação da 
resposta imune. (COZZOLINO, 2007).

A deficiência de VA está associada ao aumento do estresse oxidativo da DF, de forma que as hemácias falciformes têm capacidade de liberar o dobro de espécies reativas de oxigênio de uma hemácia normal, sendo a quantidade de antioxidantes, como a VA, insuficiente para alcançar o equilíbrio. (BEHERA, 2012). Além disso, o déficit de VA relaciona-se à degeneração testicular, queratinização do epitélio do útero, xeroftalmia, cegueira noturna, retardo na maturação sexual e esquelética e, conforme Cunha (2018), com anemia ferropriva, que agrava a DF. Essa associação entre privação de VA e DF, segundo Schall (2004), justifica o motivo do baixo nível de vitamina A estar associado a um risco 10 vezes maior de hospitalização nas crianças norte-americanas com DF.

O conhecimento dos aspectos epidemiológicos e clínicos em relação à interação entre deficiência de VA e a DF é relevante, pertinente e necessário, principalmente, quando se observa a forte relação com aumento do número de internações hospitalares. O entendimento e compreensão desse binômio possibilita a elaboração de políticas públicas de saúde mais efetivas, com potencial de mitigar os agravos que acometem o paciente com DF.

\section{OBJETIVO GERAL}

- Avaliar aspectos epidemiológicos da deficiência de vitamina A em pacientes pediátricos com DF.

\section{OBJETIVOS ESPECÍFICOS}

- Avaliar a prevalência da deficiência de vitamina A com DF.

- Caracterizar e correlacionar o valor sérico da vitamina A com aspectos antropométricos e sociodemográficos.

- Avaliar possíveis associações entre deficiência de vitamina A e complicações veno-oclusivas (úlcera maleolar, crise álgica, síndrome torácica aguda, sequestro esplênico, necrose de cabeça femoral, AVC e priapismo).

\section{MATERIAL E MÉTODOS}

Trata-se de estudo transversal observacional (estudo de prevalência) em que foram avaliados pacientes (com idades superiores a 02 anos, sem uso de dieta enteral via sonda e gestantes) de ambos os sexos, com doença falciforme acompanhados em Centro de referência em DF em Feira de Santana-BA.

Após assinatura do TCLE em conformidade com a Resolução 466/12, os sujeitos responderam a questionário estruturado acerca das características sociodemográficas e do 
histórico de complicações relacionadas à doença, acrescido da avaliação antropométrica (peso e altura).

A avaliação laboratorial da vitamina A plasmática foi realizada através da UPLC (Cromatografia Liquida de Ultra Performance), Valores menores que 0,30 ng/dl forma considerados anormais

As variáveis quantitativas, contínuas ou ordinais, foram descritas por suas medidas de tendência central (médias ou medianas) e pelas respectivas medidas de dispersão (desvio-padrão, variação interquartil ou valores mínimo e máximo), enquanto as nominais ou qualitativas por seus valores absolutos, percentagens ou proporções.

Na comparação das variáveis contínuas utilizamos o teste $t$ de Student ou o teste de Mann-Whitney ou Análise de Variância (ANOVA). Na comparação dos dados categóricos os testes de Fisher ou do qui-quadrado e suas variantes.

$\mathrm{Na}$ avaliação das correlações entre variáveis ordinais ou contínuas utilizamos o Teste de Spearman. Intervalos de confiança de 95\% foram empregados como medida de precisão dos resultados.

$\mathrm{Na}$ identificação de possíveis preditores, procedemos à análise univariada e foi realizada para as variáveis independentes qualitativas, pela comparação da frequência absoluta e percentual e para as quantitativas, da média e desvio-padrão.

A análise bivariada foi realizada para obtenção do odds ratio (OR), com respectivo intervalo de confiança de 95\% (IC 95\%), da associação entre as variáveis independentes estabelecidas e a variável dependente. Valores de $\mathrm{p}$ menores que $0,05(\mathrm{p}<0,05)$ foram considerados significativos. Nas análises, utilizamos programa estatístico computacional (GraphPad Prism, versão 8.2, GraphPad Software, San Diego-CA, USA).

\section{RESULTADOS/DISCUSSÃO}

Avaliamos 93 crianças e adolescentes com média de idade de 8,24 4,16 anos e discreta prevalência de meninas $(55,91 \%)$. O genótipo SS foi o mais frequente observado em $53,76 \%$ dos sujeitos e em sua maioria autodefinidos como pardos ou pretos $(92,47$ \%). Na amostra, 40(43,01\%) crianças apresentaram insuficiência/deficiência de VA e, os níveis séricos dos micronutrientes foram significativamente menores nos homozigóticos(SS), quando comparados aos genótipos SC/SF, respectivamente $0,27[0,21-0,34]$ e $0,38[0,29-0,43], \mathrm{p}<0,0001$. 


\section{Vitamina A}

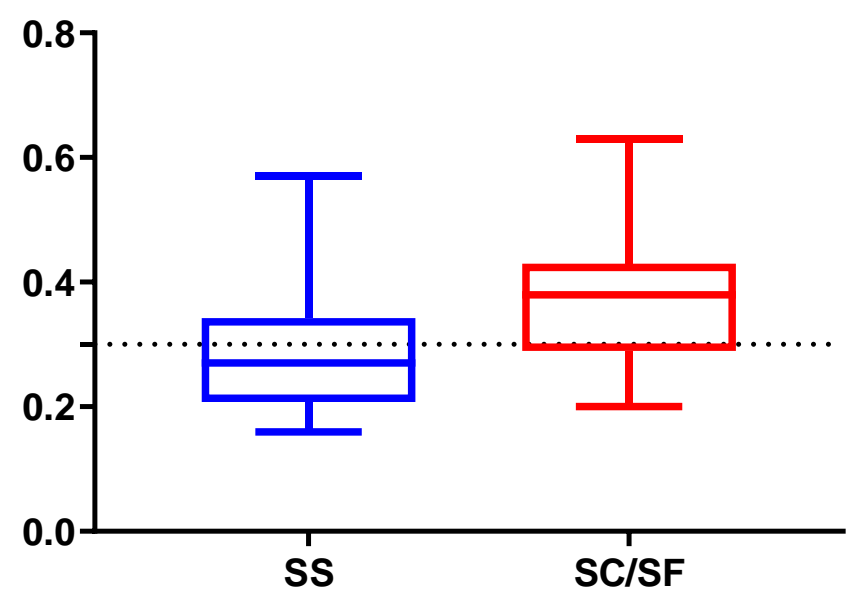

Da mesma forma significativa correlação foi observada entre os valores séricos e Vitamina A a idade ; $r=0,298$ ( $\mathrm{p}<0,004)$.

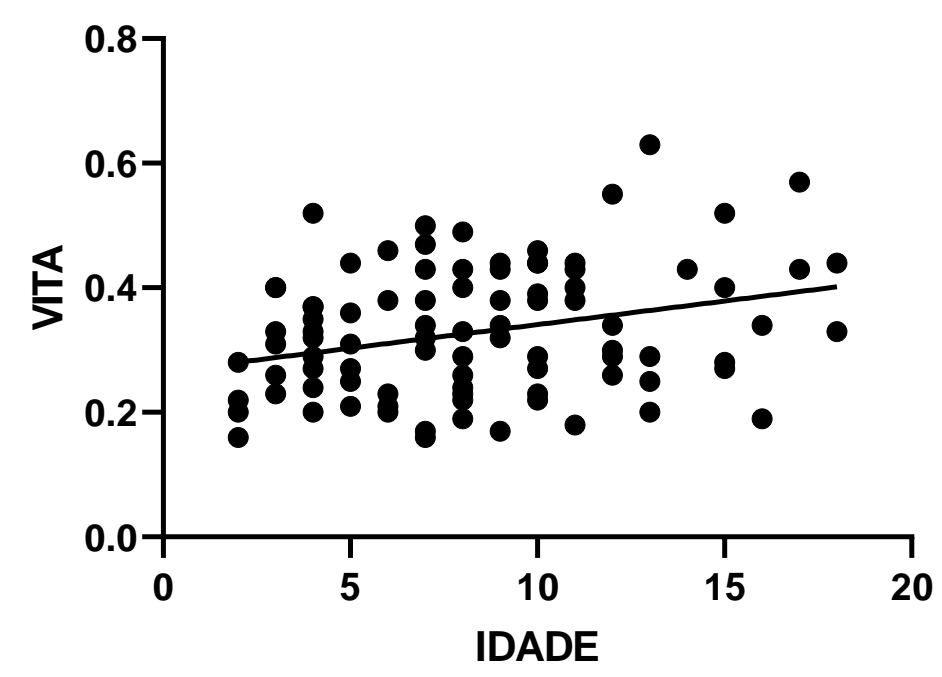

Em modelo de regressão logística, onde ajustamos para confundidores como gênero, uso de Hidroxiureia e IMC, idade e genótipo SS permaneceram independentemente associados a Hipovitaminose A. Idade com $\mathrm{OR}=0,91[0,82-0,99] \mathrm{e}$ Hemoglobina SS OR = 4,62 [1,97-8,14] IC95\%. 
O estudo, apesar de contar com a política de correção de deficiências nutricionais, através do Programa Nacional de Suplementação de Vitamina A, para crianças de 6 a 59 meses de idade (BRASIL, 2005), está em consonância com a literatura, de modo que ratifica a prevalência da deficiência de VA nos pacientes com doença falciforme. Conforme Behera et al (2012), com amostra de 80 casos, foi realizado uma avaliação semelhante a este estudo, com análise dos genótipos da anemia falciforme, em que se observou escassez de VA (concentração de retinol $<20 \mu \mathrm{g} / \mathrm{dl}$ ) maior em casos homozigotos $(46,2 \%)$ em comparação aos grupos heterozigotos $(29,2 \%)$ ou controle $(23,2 \%)$.

Natta et al (1988) realizou um estudo com 30 pacientes com doença falciforme, entre 19 e 62 anos, $10 \%$ abaixo de $20 \mathrm{mcg} / \mathrm{dl}$ e $51 \%$ abaixo de $30 \mathrm{mcg} / \mathrm{dl}$, que são considerados sub-ótimo e ótimo, respectivamente. Claster et al (2009) reafirma a deficiência de VA de 73\% (<38mcg/dl) de insuficiência em uma amostra de 43 pacientes com DF. Além disso, Schall et al (2004) realizou uma pesquisa com 66 crianças com DF do genótipo SS, com $66 \%$ de insuficiência e 17\% de deficiência, ainda nesse estudo afirma que há dez vezes maior o risco de hospitalização, relacionado a crise de dor e episódios de febre.

A dosagem da suplementação da VA para pacientes com DF ainda permanece obscura, na medida em que Dougherty et al (2012) ao realizar um estudo de suplementação, com dose recomendada para crianças normais, numa amostra de crianças com DF de genótipo SS, com $50 \%$ insuficiente e $23 \%$ deficiente, não foi notável melhoria do status, hospitalização e crescimento. A sugestão desse trabalho foi que a dosagem foi insuficiente, uma vez que o quadro de inflamação crônica e/ou perda por fezes e urina, além da própria alteração da função hepática podem estar comprometendo a manutenção dessa vitamina a níveis séricos normais.

\section{CONCLUSÃO}

A Doença Falciforme é uma hemoglobinopatia que apresenta repercussões sistêmicas, dentre outras a predisposição à deficiência de micronutrientes, como a vitamina A. Esse estudo reforça a importância da suplementação de vitamina A na população com DF, de acordo com as necessidades aumentadas desta vitamina. Além disso, destaca-se a necessidade de mais estudos acerca dessa temática, no tocante a buscar uma dosagem mais efetiva da VA, com escopo de melhorar a qualidade de vida dos pacientes com DF, com menor hospitalização e melhoria do perfil de crescimento. 


\section{REFERÊNCIAS}

1: BEHERA, S. et.al. Vitamin A status and hematological values in sickle cell disorder cases. Indian J Med Sci. Jul-Aug;66(7-8):169-74; 2012.

2: BRASIL. Ministério da Saúde. Portaria N 729/GM, 13 de maio de 2005. Vitamina A mais: Programa Nacional de Suplementação de Vitamina A. Brasília, DF: 2005 disponível em http://bvsms.saude.gov.br/bvs/saudelegis/gm/2005/prt0729_13_05_2005.html>. Acesso em: 14 jun. 2019.

3: CLASTER, S. et al. Nutritional deficiencies in iron overloaded patients with hemoglobinopathies. American Journal of Hematology, v. 84, n. 6, p. 344-348, 2009.

4: COZZOLINO, S. M. F. Biodisponibilidade de nutrientes. 4. ed. São Paulo, SP: Manole, 2012. 253-264 p.

5: CUNHA, M. S. B.; HANKINS, N. A. C.; ARRUDA, S.F. Effect of vitamin A supplementation on iron status in humans: a systematic review and meta-analysis. Crit Rev Food Sci Nutr. 2018 Jan 16:1-15.

6: DINIZ, D.; GUEDES, C. Um caso de discriminação genética: o traço falciforme no Brasil. PHYSIS: Rev. Saúde Coletiva, Rio de Janeiro, 17(3):501-520, 2007.

7: DOUGHERTY, K. et al. No improvement in suboptimal vitamin A status with a randomized, double-blind, placebo-controlled trial of vitamin A supplementation in children with sickle cell disease. The American Journal of Clinical Nutrition, 96(4), 932-940, 2012.

8: FELIX, A. A.; SOUZA, H. M.; RIBEIRO, S. B. F. Aspectos epidemiológicos e sociais da doença falciforme. Revista Brasileira de Hematologia e Hemoterapia. V. 32, n.3, p.203- 208, 2010.

9:NATTA, C. et al. Low serum levels of carotenoids in sickle cell anemia. European Journal of Haematology, 41(2), 131-135, 2009.

10: SCHALL J.I., et al. Vitamin A status, hospitalizations and others outcomes in Young children with sickle cell disease. J. Pediatr. 2004;145(1):99-106.

11: OHEMENG, A.; BOADU, I. The role of nutrition in the pathophysiology and management of sickle cell disease among children: A review of literature. Critical Reviews In Food Science And Nutrition, p. 1-7, 7 jul. 2017. 